- Lais H. C. Navarro

- Rodrigo Moreira Lima

- Norma S. P. Módolo

José R. C. Braz

\section{Efeitos do preenchimento do balonete do tubo traqueal com ar ou lidocaína a $2 \%$ alcalinizada na pressão do balonete e na morbidade laringotraqueal}

\author{
CET-SBA, Departamento de Anestesiologia da Faculdade de Medicina \\ da Universidade Estadual Paulista, Botucatu, São Paulo
}

INTRDDUÇÃa

A hiperinsuflação do balonete do tubo traqueal (TT), causada pela difusão do óxido nitroso $\left(\mathrm{N}_{2} \mathrm{O}\right)$, pode determinar lesôes traqueais, que se manifestam clinicamente como odinofagia, rouquidão e tosse. A lidocaína, quando injetada no balonete, determina ação anestésica local na traquéia.

MÉTODOS

Cinqüenta pacientes foram submetidas à anestesia geral, sendo distribuídas em dois grupos, de acordo com o preenchimento do balonete: grupo $\operatorname{Ar}(\mathrm{n}=25)$ - preenchido com ar e grupo Lido $(\mathrm{n}=25)$ - preenchido com lidocaína alcalinizada. A medida da pressão do balonete foi realizada por manômetro digital no grupo Ar e por transdutor de pressão Hewlett-Packard no grupo Lido, antes e após 30, 60, 90 e 120 minutos do início da inalação de $\mathrm{N}_{2} \mathrm{O}$, bem como ao final da anestesia, antes da interrupção da inalação do $\mathrm{N}_{2} \mathrm{O}$. Ao término do procedimento, as pacientes foram encaminhadas à sala de recuperação pós-anestésica, onde avaliou-se a presença de manifestações clínicas relacionadas ao emprego do TT, também avaliada no primeiro dia de pós-operatório (PO). $\mathrm{Na}$ análise estatística, valores de $\mathrm{p}<0,05$ foram considerados significativos.

RESULTADIS

Os grupos mostraram-se homogêneos quanto às variáveis antropométricas, ASA, duração da anestesia e da intubação traqueal. Os valores da pressão no balonete no grupo Lido foram significativamente menores do que os do grupo Ar a partir de 30 minutos de estudo $(p<0,05)$. A proporção de pacientes que reagiu ao TT no momento da desintubação foi notavelmente menor no grupo da lidocaína $(p<0,05)$, assim como a incidência de odinofagia 24 horas após a desintuba- ção traqueal $(\mathrm{p}<0,05)$. A incidência de tosse e rouquidão não diferiu entre os grupos. A pressão arterial sistólica (PAS) teve aumento significativamente menor no grupo Lido, no momento da desintubação $(\mathrm{p}<0,05)$.

DISCUSSÃロ

Com a alcalinização do cloridrato de lidocaína, o balonete do TT pôde constituir-se em verdadeiro reservatório de liberação do anestésico local para os tecidos traqueais subjacentes. Além da prevenção da hiperinsuflação do balonete, outra vantagem fundamental do emprego da lidocaína alcalinizada foi a diminuição da morbidade laringotraqueal. Houve aumento significativo da tolerância ao tubo traqueal, demonstrado pela menor incidência de agitação, bem como pelo aumento significativamente menor da pressão arterial sistólica no momento da desintubação.

CロNCLUSÃロ

Durante a ventilação artificial, com a mistura de $\mathrm{O}_{2} / \mathrm{N}_{2} \mathrm{O}$, a insuflação do balonete com lidocaína $2 \%$ alcalinizada impede que ocorra aumento significativo da pressão no balonete e determina maior tolerância ao TT, com menor incidência de agitação e menor aumento da PAS no momento da desintubação, além de menor incidência de odinofagia no PO.

REFERÊNCIA

1. Fagan C, Frizelle HP, Laffey J, Hannon V, Carey M. The effects of intracuff lidocaine on endotracheal-tube-induced emergence phenomena after general anesthesia. Anesth Analg. 2000;91:201-5

Endereço para correspondência:

Rodrigo Moreira Lima

Distrito de Rubião Júnior - Caixa Postal 530

Botucatu (SP) - CEP 18618-970 